\title{
Effectiveness of Lateral Insoles in Improving Activity of Daily Living Among Patients of Knee Osteoarthritis
}

\author{
Abdulsalam 1 , Waqar Ahmed Awan², Aqsa Khalid ${ }^{3}$, Tahir Mahmood ${ }^{4}$, Muhammad Waqas Ghauri ${ }^{5}$ \\ ${ }^{1}$ Assistant Professor/HOD, Imran Idrees Institute of Rehabilitation Sciences, Sialkot Medical College, Sialkot \\ ${ }^{2}$ Consultant Physical therapist, Rehab Active, I -8 Active Fitness Center Islamabad -Pakistan \\ ${ }^{3}$ Medical Officer, Sundas Foundation, Sialkot Pakistan \\ 4 Senior Lecturer /Physical Therapist, Imran Idrees Institute of Rehabilitation Sciences, Sialkot Medical College, Sialkot \\ ${ }^{5}$ Assistant professor, Agile Institute of Rehabilitation Sciences, Bahawalpur Punjab Pakistan
}

\begin{abstract}
Author's Contribution
1-2Conception and design, Collection and assembly of data, ${ }^{3}$ Drafting of article, Analysis and interpretation of the data, ${ }^{4-5}$ Critical revision of the article for important intellectual content, ${ }^{4}$ Statistical expertise ${ }^{3}$ Final approval and guarantor of the article.

Article Info.

Received: Sep 09, 2021

Acceptance: Nov 29, 2021

Conflict of Interest: None

Funding Sources: None

Address of Correspondence

Abdul Salam

Email Id: abdulsalamrana@yahoo.com

ORIC Id: 0000-0001-8887-3575
\end{abstract}

Cite this article as Abdulsalam, Awan WA, Khalid A, Mahmood T, Ghauri MW. Effectiveness of Lateral Insoles in Improving Activity of Daily Living Among Patients of Knee Osteoarthritis. JRCRS. 2021; 9(2):79-

83.

DOI: $10.53389 / J R C R S .2021090209$

\section{Introduction}

Osteoarthritis $(\mathrm{OA})$ the most prevalent of the chronic rheumatic disease. Most commonly, effecting women more than males, leading to disability. Overall it exists in $28.7 \%$ and female prevalence was $31.6 \% .^{1}$ There are near to $13 \%$ of the females and males aged 60 years have $10 \%$ and older have symptomatic knee $\mathrm{OA}$. The ratio of the population affected by $\mathrm{OA}$ with symptoms, the knee is most likely to be increased due to the age related of that population and their ratio of obesity or overweight in comparison to the general population ${ }^{2}$ especially those of above 55 years, have more severe OA in the knee as compared to the other joints in their body. The prevalence of

\section{A B S T R A C T}

Objective: To determine the effectiveness of lateral insoles in patients of Knee Osteoarthritis for improving activities of daily living among patients with Knee Osteoarthritis.

hodology: This a single blinded, Randomized controlled clinical trial conducted on 40 at Madinah Teaching Hospital, physiotherapy clinics from 25 Feb 2016 to 26 method subjects were recruited and randomized using coin toss method into group $A$ and B. The study was completed in 07 months. Subjects diagnosed with Osteoarthritis (OA) on he basis of clinical and radiological finding of medial compartment knee OA grade II and III ere included. Subjects were included as per inclusion criteria of study and then divided in groups with 20 subjects in each. Activity of daily living was assessed at baseline, 2nd, outcome of interest.

Results: The results showed that there was significant improvement in activities including bathing, standing, and sitting, getting in and out of car and ascending chairs. The experimental group treated with lateral Insoles, showed greater improvement comparing pre and post intervention as compared to control group $(\mathrm{P}<.05)$

Conclusion: The results of the study show that the lateral insoles have significant role for improving the activity of daily living in patients having grade III knee Osteoarthritis.

Key words: ADLS, Knee Osteoarthritis, Lateral Insoles
$\mathrm{OA}$ in the knee joint is affected by postmenopausal factors and gender differences. ${ }^{3}$ The prevalence was found to be high based on the findings from radiographic results of Knee arthritic changes. The incidence was more in females than that of the men4 knee arthritic symptoms were mostly in the general young was less but mostly found in women of older age. In a study Greece community, knee OA symptoms were observed.5,1 The incidence rate was much higher in the females than in males and ratio was increased significantly with respect to age. Symptoms of OA in knee were not common in urban compared to rural and suburban study population.Obesity and a lower level of education were linked 
in the knee OA involved population. ${ }^{7}$ There were Knee symptoms, radiographic changes in knee $O A$, knee $O A$ with its symptoms, and severe radiographic knee $O A$ were added in 3018 participants of study (33\%) in population of African and Americans (38\% men). The Diagnosis of OA and its severity disease is usually based on Kellgren -Lawrence radiographic grade above II, severe radiographic knee OA classified as 3 grades and 4 grades, and symptomatic knee $O A$ as knee symptoms in a knee with radiographic OA. ${ }^{8}$ The symptoms in knee were found in $43 \%$ of population. $28 \%$ of patients having symptoms had changes in their radiographs of knee, but less ratio with symptomatic knee OA were $16 \%$ only, and only $8 \%$ of them have high changes in radiographs of knee $O A$.

Incidence was found more in older adults and women, but prevalence was higher of end stage findings as per radiographic knee $\mathrm{OA}$ than that according to literature available in studies. ${ }^{9}$ The symptoms leading to concerns of Knee arthritis were due to higher body mass index, less education, increase in morbidity, activity limitations and joint space tenderness. All these can lead to increase in pain and limited activities of daily living. ${ }^{10}$ These symptoms need to be managed using different interventional strategies using isometrics, traction, gliding, failure of these conservative need surgical or knee replacement procedures. ${ }^{11}$ In a local study, it was reported that $40 \%$ had effected $26-50 \%$ quality of life due Osteoarthritis ,while $23.8 \%$ had severely affected their life activities due Knee $\mathrm{OA}^{12}$ The lateral wedge insoles, a specific design that can induce difference of stiffness that can lead to decrease in adduction of knee along with the ankle/subtalar eversion reduction. ${ }^{13}$ Nature has created an organised and balanced pattern of movements, but any underlying cause changes it that need conservative or surgical methods based on evidence. The purpose of this study was to measure the effects of lateral insoles in patients with knee osteoarthritis, so that they can be given a new strategy to live an improved activity of daily livings with decrease in symptoms due to knee Osteoarthritis.

\section{Methodology}

This single blind randomized controlled trail, was conducted after ethical permission from Isra University, Islamabad from 15 Feb 2016 to Aug 2016. In the first step participant were selected through non- purposive convenient sampling. 53 patients were enrolled, $\left({ }^{14}\right)$ but 40 patients were considered for the conduction of this study. Before the start of their participation in the study, all the participants were informed about the study and its purpose. After their signed consent they were allowed to participate in the study. Subjects having Knee osteoarthritis patients with medial joint space reduction, male and female adults with osteoarthritis between $40-60{ }^{15}$ years of age, clinically and radiological based diagnosed cases of knee $\mathrm{OA}$ grade II and III were included ${ }^{16}$ All the subjects with rheumatoid Arthritis, physical deformity, trauma in last 6 months, fracture of knee, systemic disease leading to knee pain and age less than 40 or greater than 60 years were excluded. After initial assessment all the subjects were recruited in two groups by coin toss method to remove chance of allocation Bias.

In Experimental group (A) Lateral insoles (of thickness $7 \mathrm{~mm})^{17}$ were given and instructed to wear the shoes during day time throughout the week. The insoles were placed in the shoes and adjusted and they were also given same routine treatment as in control group. The control group (B) received ,Short Wave Diathermy (SWD)( for15 minutes), therapeutic ultrasound ${ }^{18}$ and Knee isomeric exercises (for 15 minutes), session was given for 35 minutes, for 5 times in a week for 6 weeks. The therapeutic ultrasound was given at 1.5 watts $/ \mathrm{cm}^{2}$ for 5 minutes at continues mode. All these protocols are already available in literature and proved to be an effective regimen. The data from subjects was collected after explaining them the purpose of study and signing informed consent. Their Knee functioning was assessed by using ADLs Questionnaire of knee survey that consists of items for daily living including getting out car, standing ,ascending and descending chairs. ${ }^{19}$ The assessor was asked to measure their ADL; $s$ for baseline evaluative data. The assessor was blinded and was not aware of the group. Data was taken before, mid and end i.e. 2nd, 4th and 6th weeks respectively. Demographic data i.e. age, gender and baseline data of subjects were taken at zero visits. The intervention was given for 6 weeks; the outcome was measured at baseline, 2nd, 4th and $6^{\text {th }}$ week. Using SPSS V. 20, appropriate statistical tests were used according to data distribution. The Repeated measurement ANOVA used for group comparisons.

Results

There were $82.5 \%$ males while $17.5 \%$ were female participants with mean age $54.18 \pm 5.90$. The mean score of symptom of going up and down at baseline in experimental group was $3.55 \pm .51$ while in the control group $4.00 \pm 0.00$. The mean score was improved to $1.10 \pm 0.57$ experimental and $3.00 \pm 0.000$ of control group on $6^{\text {th }}$ week of evaluation. In ascending stairs at baseline experimental group was $3.55 \pm 0.510$ while in control group was $4.00 \pm 0.00$ and reduced to $1.10 \pm 0.57$ in experimental and $3.00 \pm 0.000$ in control group at $6^{\text {th }}$ week. The $p$ value was $<0.05$ showing a statistical significant effect of intervention in both groups. (Table No I) 


\begin{tabular}{|c|c|c|c|c|}
\hline \multirow{2}{*}{\multicolumn{5}{|c|}{$\begin{array}{l}\text { Table I: Descriptive Statistics of Going-up/do } \\
\text { ascending stairs with pain experience } \\
\text { Descriptive Statistics between the group }\end{array}$}} \\
\hline & & & & \\
\hline ADL's & $\begin{array}{l}\text { Time } \\
\text { point }\end{array}$ & Groups & $\begin{array}{l}\text { Mean Std. } \\
\text { Deviation }\end{array}$ & $\begin{array}{c}\text { P. } \\
\text { value }\end{array}$ \\
\hline \multirow{8}{*}{$\begin{array}{l}\text { Pain while } \\
\text { going } \\
\text { up/down }\end{array}$} & & Experimental & $3.55+0.51$ & \multirow{8}{*}{0.00} \\
\hline & Baseline & Control & $4.00 \pm 0.00$ & \\
\hline & \multirow[b]{2}{*}{$2^{\text {nd }}$ week } & Experimental & $2.70+0.57$ & \\
\hline & & Control & $3.45 \pm 0.51$ & \\
\hline & \multirow[b]{2}{*}{$4^{\text {th }}$ week } & Experimental & $2.15 \pm 0.67$ & \\
\hline & & Control & $3.00+0.00$ & \\
\hline & \multirow[b]{2}{*}{$6^{\text {th }}$ week } & Experimental & $1.65 \pm 0.98$ & \\
\hline & & Control & $3.25+0.44$ & \\
\hline \multirow{8}{*}{$\begin{array}{l}\text { ADL's } \\
\text { ascending } \\
\text { stair }\end{array}$} & \multirow[b]{2}{*}{ Baseline } & Experimental & $3.45 \pm 0.94$ & \multirow{8}{*}{0.00} \\
\hline & & Control & $3.75+0.44$ & \\
\hline & \multirow{3}{*}{$2^{\text {nd }}$ week } & Experimental & $2.70+0.73$ & \\
\hline & & Control & $3.45 \pm 0.51$ & \\
\hline & & Experimental & $2.25+0.71$ & \\
\hline & $4^{\text {th }}$ week & Control & $3.10 \pm 0.30$ & \\
\hline & \multirow[b]{2}{*}{$6^{\text {th }}$ week } & Experimental & $1.70 \pm 0.86$ & \\
\hline & & Control & $2.75 \pm 0.44$ & \\
\hline
\end{tabular}

\begin{tabular}{|c|c|c|c|c|}
\hline \multicolumn{5}{|c|}{$\begin{array}{l}\text { Table II: Descriptive Statistics of ADL's standing, bending } \\
\text { and getting in/out of bath pain experience }\end{array}$} \\
\hline \multicolumn{5}{|c|}{ Descriptive Statistics between the group } \\
\hline ADL's & $\begin{array}{l}\text { Time } \\
\text { point }\end{array}$ & Groups & $\begin{array}{l}\text { Mean Std. } \\
\text { + Deviation }\end{array}$ & $\begin{array}{c}\text { P- } \\
\text { value }\end{array}$ \\
\hline \multirow{8}{*}{$\begin{array}{l}\text { ADL'S } \\
\text { standing }\end{array}$} & \multirow[b]{2}{*}{ Baseline } & Experimental & $3.50 \pm 1.00$ & \multirow{8}{*}{0.00} \\
\hline & & Control & $3.50+0.88$ & \\
\hline & \multirow{2}{*}{$\begin{array}{l}\text { 2nd } \\
\text { week }\end{array}$} & Experimental & $2.75 \pm 0.63$ & \\
\hline & & Control & $3.50+0.51$ & \\
\hline & \multirow{2}{*}{$\begin{array}{l}\text { 4th } \\
\text { week }\end{array}$} & Experimental & $2.10 \pm 0.78$ & \\
\hline & & Control & $3.25+0.44$ & \\
\hline & \multirow{2}{*}{$\begin{array}{l}\text { 6th } \\
\text { week }\end{array}$} & Experimental & $1.50+0.76$ & \\
\hline & & Control & $2.75 \pm 0.44$ & \\
\hline \multirow{8}{*}{$\begin{array}{l}\text { ADL'S } \\
\text { bending }\end{array}$} & \multirow[t]{2}{*}{ Baseline } & Experimental & $3.45+0.99$ & \multirow{8}{*}{0.00} \\
\hline & & Control & $3.50 \pm 0.88$ & \\
\hline & \multirow{2}{*}{$\begin{array}{l}\text { 2nd } \\
\text { week }\end{array}$} & Experimental & $2.85 \pm 0.58$ & \\
\hline & & Control & $3.60+0.50$ & \\
\hline & \multirow{2}{*}{$\begin{array}{l}\text { 4th } \\
\text { week }\end{array}$} & Experimental & $2.10+0.78$ & \\
\hline & & Control & $3.25+0.44$ & \\
\hline & \multirow{2}{*}{$\begin{array}{l}\text { 6th } \\
\text { week }\end{array}$} & Experimental & $1.75+0.71$ & \\
\hline & & Control & $2.85+0.58$ & \\
\hline \multirow{8}{*}{$\begin{array}{l}\text { ADL's } \\
\text { getting } \\
\text { in/out of } \\
\text { bath }\end{array}$} & \multirow[t]{2}{*}{ Baseline } & Experimental & $3.45 \pm 0.75$ & \multirow{8}{*}{0.00} \\
\hline & & Control & $3.50 \pm 0.51$ & \\
\hline & \multirow{2}{*}{$\begin{array}{l}\text { 2nd } \\
\text { week }\end{array}$} & Experimental & $2.45+0.60$ & \\
\hline & & Control & $3.50+0.51$ & \\
\hline & \multirow{2}{*}{$\begin{array}{l}\text { 4th } \\
\text { week }\end{array}$} & Experimental & $1.80+0.69$ & \\
\hline & & Control & $3.40 \pm 0.50$ & \\
\hline & \multirow{2}{*}{$\begin{array}{l}\text { 6th } \\
\text { week }\end{array}$} & Experimental & $1.15+0.74$ & \\
\hline & & Control & $3.00+0.72$ & \\
\hline
\end{tabular}

In standing at baseline in experimental group was $3.55 \pm$ 0.510 while the score amongst the control group was $4.00 \pm 0.00$. On last evaluation at $6^{\text {th }}$ week the mean was $1.10 \pm 0.57$ in experimental and $3.00 \pm 0.000$ in control group. In getting in and out at baseline in experimental group was $3.55 \pm 0.510$ while control group mean was $4.00 \pm 0.00$. (Table No II)

The group comparison shows that experimental group receiving routine therapy with lateral insoles has statistically significant difference with $p$ value $<0.05$. (Table. No. III)

\begin{tabular}{|c|c|c|c|c|c|}
\hline \multicolumn{6}{|c|}{$\begin{array}{c}\text { Table III: Descriptive statistics for Sum of ADL's in each } \\
\text { phase }\end{array}$} \\
\hline & & \multicolumn{2}{|c|}{$\begin{array}{c}\text { Group A } \\
\text { (Lateral Insoles) }\end{array}$} & \multicolumn{2}{|c|}{$\begin{array}{c}\text { Group B } \\
\text { (Routine +Lateral } \\
\text { Insoles) }\end{array}$} \\
\hline & & $\begin{array}{l}\text { Mean } \pm \\
\text { SD }\end{array}$ & $\begin{array}{c}\mathrm{p}- \\
\text { value }\end{array}$ & $\begin{array}{c}\text { Mean } \\
\text { SD }\end{array}$ & $\begin{array}{c}\mathrm{p}- \\
\text { value }\end{array}$ \\
\hline \multirow{7}{*}{ 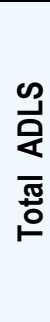 } & $\begin{array}{c}\text { At } \\
\text { Baseline }\end{array}$ & $\begin{array}{c}10.9 \pm \\
10.2\end{array}$ & 0.00 & $11.40 \pm 8.52$ & 0.00 \\
\hline & $2^{\text {nd }}$ & $31.4 \pm$ & & $13.05 \pm 6.42$ & \\
\hline & Week & $10.1 \overline{7}$ & & & \\
\hline & $4^{\text {th }}$ & $34.4 \pm$ & 0.00 & $13.05 \pm 6.42$ & 0.00 \\
\hline & Week & 11.21 & & & \\
\hline & $6^{\text {th }}$ & $47.8 \pm$ & & $18.90 \pm$ & \\
\hline & Week & 11.44 & & 4.25 & \\
\hline \multicolumn{6}{|c|}{ ADLs=Activity of Daily Livings, $P$ value was significant at $<0.05$} \\
\hline \multicolumn{6}{|c|}{ Discussion } \\
\hline
\end{tabular}

The results of the study showed that there was significant improvement in activities including bathing ,standing, sitting, getting in and out of car, socks wearing as well as ascending chairs. This finding suggests that the subgroup may have compensated at the rear foot for the orthotic differently than the majority of the subjects. These subjects may have accounted for the lack of significance found in peak knee adduction. ${ }^{20}$ Knee adduction excursion was significantly reduced even though the mean reduction was 0.7 degrees. However, 12 of 20 subjects exhibited at least a 10\% reduction. The clinical relevance of such a small reduction in knee adduction excursion may be questioned. Gustavo et all 21 prospectively applied it at baseline and at weeks 2,8 and 24. At weeks 8 and 24, both groups showed lower scores for WOMAC $(P=0.023$ and $P=0.012$ respectively). Pain was significantly reduced in both the group. Similarly according to our study mean age of all patients were $55.05 \pm 6.7$ years while sensation of pain at knee joint due to osteoarthritis was reduced. As in zero week within experimental group the total pain score mean was $79.9 \pm 2.2$ while on final session the total pain score mean was $91.4 \pm 4.2$ as discussed earlier that 100 shows perfect condition while 0 means worst condition further suggested by $P$ value $=0.01$. In recent study, by M.T Khan comparative effects of insoles proved in this year to be the best for joint biomechanics modification. It has been proved that lateral insoles are effective management of knee OA. ${ }^{22}$ 
In one of the study on Quality of life improvement among patients of Knee Osteoarthritis, it was linked to biomechanical loading factors was modified and improvement was seen but that's was reduction of infra-pattaler pads. ${ }^{23,24}$ Similarly our study was also focused on biomechanical factors and change in biomechanics of knee by using lateral insoles so that load can be decreased on the joint which can help to some extent in performing ADLs. In one of the study foot orthotics were compared with flat insoles. The study concluded that there was no significant difference between them but flat were quite comfortable as compared to that of the foot orthotics. The value of $p>0.05$ ( flat shoes or flat insoles).Pain was also reduced when they assessed shoes alone, foot orthotics $(p=0.002)$ but flat insoles $(p<0.001)$ there was reduced pain during stepdowns; foot orthotics reduced pain during walking $(p=0.008$; 1and flat insoles reduced pain for ambulation during stairs $(p=0.001)$. No significant differences between foot orthotics and flat insoles were observed for pain severity, ease of performance or knee stability. It concluded that immediate painrelieving effects of prefabricated flat insoles were equal to foot orthotics. ${ }^{25}$ Similarly in our experimental group was mean at pre session $3.55 \pm 0.510$ compared to end session was $2.15 \pm$ 0.67 . This study was found to be in favor of our results. In contrast to another study, another study found that insoles can reduce pain but the reported effect size was less and considered less significant clinically ${ }^{26}$ We have focused on biomechanical factor but resistance training can also play an effective role in reduction of stiffness as well as Activities of daily livings , but isotonic exercise are considered dominant on it. ${ }^{27}$ The study was conducted on fewer samples. Such studies should be continued at larger samples, so that results can be generalized in other populations as well. Less data from the females can affect the generalization of result.

\section{Conclusion}

The current study results concluded the lateral insoles are significant in improving the activity of daily living among patients with knee Osteoarthritis to a level that can improve their ADLs towards improvement.

Recommendations: There should be studies with larger samples in various populations and regions to rule out if there are others affect the outcomes.

Acknowledgement: We are thankful to Dr. Ahmad Bilal Arif (HOD) and $\mathrm{Dr}$.Muhammad Mohsin Hussain, Assistant professor SRS, The University of Faisalabad for their help in data collection and support.

References
1. Pal CP, Singh $P$, Chaturvedi $S$, Pruthi KK, Vij A. Epidemiology of knee osteoarthritis in India and related factors. Indian journal of orthopaedics. 2016;50(5):518.

2. Heidari BJCjoim. Knee osteoarthritis prevalence, risk factors, pathogenesis and features: Part I. 2011;2(2):205.

3. Anandkumar $S$, Sudarshan $S$, Nagpal P. Efficacy of kinesio taping on isokinetic quadriceps torque in knee osteoarthritis: a double blinded randomized controlled study. Physiotherapy theory and practice. 2014;30(6):37583.

4. Muraki S, Akune T, Oka H, Ishimoto Y, Nagata K, Yoshida $M$, et al. Incidence and risk factors for radiographic knee osteoarthritis and knee pain in Japanese men and women: A longitudinal population-based cohort study. Arthritis \& Rheumatism. 2012;64(5):1447-56.

5. Malemud CJ. Cytokines as therapeutic targets for osteoarthritis. BioDrugs. 2004;18(1):23-35.

6. Bennell KL, Bowles K-A, Payne C, Cicuttini F, Williamson $E$, Forbes $A$, et al. Lateral wedge insoles for medial knee osteoarthritis: 12 month randomised controlled trial. Bmj. 2011;342:d2912.

7. Andrianakos AA, Kontelis LK, Karamitsos DG, Aslanidis SI, Georgountzos Al, Kaziolas GO, et al. Prevalence of symptomatic knee, hand, and hip osteoarthritis in Greece. The ESORDIG study. The Journal of rheumatology. 2006;33(12):2507-13.

8. Kohn MD, Sassoon AA, Fernando ND. Classifications in brief: Kellgren-Lawrence classification of osteoarthritis. Springer; 2016.

9. Jordan JM, Helmick CG, Renner JB, Luta G, Dragomir AD, Woodard $\mathrm{J}$, et al. Prevalence of knee symptoms and radiographic and symptomatic knee osteoarthritis in African Americans and Caucasians: the Johnston County Osteoarthritis Project. The Journal of rheumatology. 2007;34(1):172-80.

10. Bastick AN, Wesseling J, Damen J, Verkleij SP, Emans PJ, Bindels PJ, et al. Defining knee pain trajectories in early symptomatic knee osteoarthritis in primary care: 5 year results from a nationwide prospective cohort study (CHECK). Br J Gen Pract. 2016;66(642):e32-e9.

11. Soleman Warner AA, Afzal MW, Khan S, Aslam MM, Gillani SA. Comparison of routine physical therapy exercises with and without core stability exercises in total knee replacement patients. Rawal Medical Journal. 2020;45(4).

12. Saeed A, Zulfiqar T, Kaleem M, Hafeez M, Ghauri MW. Health related quality of life in patients with grade III knee osteoarthritis. Rawal Medical Journal. 2021 Jul;46(3):5803.

13. Calvin TF, Ryan MB, Hunt MA. Influence of foot posture on immediate biomechanical responses during walking to variable-stiffness supported lateral wedge insole designs. Gait \& Posture. 2020 Sep 1;81:21-6.

14. Kheshie, A.R., Alayat, M.S.M. \& Ali, M.M.E. High-intensity versus low-level laser therapy in the treatment of patients with knee osteoarthritis: a randomized controlled 
trial. Lasers Med Sci 29,1371-1376 (2014). https://doi.org/10.1007/s10103-014-1529-0

15. Bijlsma J, Knahr KJBP, Rheumatology RC. Strategies for the prevention and management of osteoarthritis of the hip and knee. 2007;21(1):59-76.

16. Muhammad A, Azam MJ, Salam A. Impact On Quality Of Life In Patients With Knee Osteaoarthritis In Faisalabad. Journal of University Medical \& Dental College. 2018;9(3):49-52.

17. Sawada T, Kito N, Yukimune M, Tokuda K, Tanimoto K, Anan M, Takahashi M, et al. Biomechanical effects of lateral and medial wedge insoles on unilateral weight bearing. Journal of physical therapy science. 2016;28(1):280-5.

18. Cetin N, Aytar A, Atalay A, Akman MN. Comparing hot pack, short-wave diathermy, ultrasound, and TENS on isokinetic strength, pain, and functional status of women with osteoarthritic knees: a single-blind, randomized, controlled trial. American journal of physical medicine \& rehabilitation. 2008 Jun 1;87(6):443-51.

19. Salam A, Awan MW, Mahmood T, Rukh MS, Seffat N. Application of Lateral Wedge in Knee Osteoarthritis for Improving Pain and Quality of Life. Journal of Liaquat University of Medical \& Health Sciences. 2019;18(02):14651.

20. de Figueiredo ECQ, Figueiredo GC, Dantas RT. Influência de elementos meteorológicos na dor de pacientes com osteoartrite\&58; revisão da literatura Influence of meteorological elements on osteoarthritis pain\&58; a review of the literature. Revista Brasileira de Reumatologia. 2011;51(6):622-8.
21. Campos GCd, Rezende MU, Pasqualin T, Frucchi R, Bolliger Neto R. Lateral wedge insole for knee osteoarthritis: randomized clinical trial. Sao Paulo Medical Journal. 2015;133(1):13-9.

22. Khan M. A comparative study of the effects of lateral wedge insole shoe modification on the patients with knee osteoarthritis. Osteoarthritis and Cartilage. 2018;26:S328.

23. Santangelo KS, Radakovich LB, Fouts J, Foster MT. Pathophysiology of obesity on knee joint homeostasis: contributions of the infrapatellar fat pad. Hormone molecular biology and clinical investigation. 2016;26(2):97108.

24. Diepold J, Ruhdorfer A, Dannhauer T, Wirth W, Steidle E, Eckstein $F$. Sex-differences of the healthy infra-patellar (Hoffa) fat pad in relation to intermuscular and subcutaneous fat content-data from the Osteoarthritis Initiative. Annals of Anatomy-Anatomischer Anzeiger. 2015;200:30-6.

25. Collins NJ, Hinman RS, Menz HB, Crossley KM. Immediate effects of foot orthoses on pain during functional tasks in people with patellofemoral osteoarthritis: a cross-over, proof-of-concept study. The Knee. 2017;24(1):76-81.

26. Felson DT, Parkes M, Carter S, Liu A, Callaghan MJ, Hodgson R, Bowes M, Jones RK. The efficacy of a lateral wedge insole for painful medial knee osteoarthritis after prescreening: a randomized clinical trial. Arthritis \& Rheumatology. 2019 Jun;71(6):908-15.

27. Saeed HH, Atif MM, Afzal F, Hussain S, Umer MI, Rasul A. Eccentric versus concentric isotonic resistance training of quadriceps muscles for treatment of knee osteoarthritis. Rawal Medical Journal. 2021 Jan;46(1):52-5.

\section{Copyright Policy}

All Articles are made available under a Creative Commons "Attribution-NonCommercial 4.0 International" license. (https://creativecommons.org/licenses/by-nc/4.0/). Copyrights on any open access article published by Journal Riphah college of Rehabilitation Science (JRCRS) are retained by the author(s). Authors retain the rights of free downloading/unlimited e-print of full text and sharing/disseminating the article without any restriction, by any means; provided the article is correctly cited. JRCRS does not allow commercial use of the articles published. All articles published represent the view of the authors and do not reflect the official policy of IRCRS 